\title{
Os implicativos do adoecimento e afastamento laboral de trabalhadoras do ramo têxtil em decorrência de doenças osteomusculares ocupacionais
}

\author{
Cristiane Lenita Rhoden do Nascimento ${ }^{1}$ \\ Karin Cristiane Freitag ${ }^{2}$
}

\section{INTRODUÇÃO}

Este texto apresenta resultados de uma pesquisa que foi originada no curso de graduação de Serviço Social da Universidade Regional de Blumenau (FURB). Nesta produção de conhecimento, buscou-se analisar os impactos trazidos pelas doenças osteomusculares ocupacionais para a vida de trabalhadoras de uma empresa têxtil de Blumenau/SC, as quais estavam afastadas das atividades laborais em decorrência de seu adoecimento e os efeitos gerados a elas, na perspectiva do contexto social, familiar e os reflexos no cotidiano.

A metodologia aplicada à pesquisa foi teórico-empírica, de abordagem qualitativa, utilizou-se a entrevista semiestruturada como técnica de coleta de dados na empresa e pesquisa bibliográfica.

Os resultados da pesquisa apresentam as problemáticas observadas neste cenário, dentre elas, as construções desiguais de gênero, limitações impostas pela condição de empobrecimento, exploração da mulher na sociedade contemporânea, além da condição de adoecimento em virtude do modo de produtividade da lógica capitalista.

Neste sentido, tornam-se importantes pesquisas que se propõem a estudar o mundo do trabalho, a saúde do trabalhador e as relações de gênero e familiares.

\footnotetext{
${ }^{1}$ Graduada em Serviço social pela FURB e Assistente Social atuante em Políticas Públicas no município de Gaspar/SC. E-mail: cris.lenita@hotmail.com

${ }^{2}$ Mestre em Desenvolvimento Regional (FURB-SC), atuou como Assistente Social em empresa privada e atualmente é Assistente Social em Políticas Públicas no município de Blumenau. E-mail: $\underline{\text { karin_Freitag@yahoo.com.br }}$
} 


\section{O MUNDO DO TRABALHO E O PROCESSO DE ADOECIMENTO DAS TRABALHADORAS DA INDÚSTRIA TÊXTIL}

A reestruturação produtiva, sustentada por novas formas de gestão, passou a fazer parte do cotidiano industrial desde 1980, projetando-se no Japão e reafirmando-se na década seguinte, pulverizando-se por outros países e regiões, impondo novo ritmo de trabalho, produtividade, qualificação do produto, aumentando a tensão laboral, gerando incertezas e promovendo o aparecimento de 'novas doenças', principalmente na esfera mental, que coexistem com as 'velhas doenças', como, por exemplo, lesões por esforços repetitivos, estresse e depressão. A condição de adoecimento fragiliza as pessoas e a expõem inúmeros desafios, como bem expressa Lourenço:

\footnotetext{
Portanto, o estar ou ter uma doença é uma contingência vital e social que, por juízo de valor da sociedade moderna do trabalho e de classe, tornou-se uma condição ou atributo permanente negativo que carrega consigo a acusação do sujeito ser socialmente um peso morto. Ou seja, são normais os que suportam agravos e agressões sem gemidos e protestos; são anormais, predispostos, suscetíveis, inadaptáveis, ou doentes os que não os aguentam e manifestam mal-estar e sofrimento. (2010, p.307)
}

De acordo com Antunes (2009, p.261) “(...) o trabalho que estrutura o capital desestrutura o ser social" e lhe impõem condições ainda mais perversas de exploração e subordinação, conforme se moderniza o capital e se atualiza as formas de extração de maisvalia, desrespeitando inclusive os limites impostos pela condição física e psíquica do trabalhador. No entanto, o indivíduo não é somente um ser biológico, mas um ser social, o qual necessita do trabalho como fator importante de sociabilidade. Então compreendemos que,

A partir da premissa epistêmica que entende o trabalho enquanto categoria central da sociabilidade humana, presumimos que o novo metabolismo social do trabalho na contemporaneidade se vê diante de novos modos de (des) constituição do ser genérico do homem. Com isso, num processo social onde o adoecimento laboral ganha contornos singulares, num contexto de ampla e intensificada exploração da força de trabalho e de espoliação da corporalidade viva (corpo e mente) do trabalhador, evidenciamos que o olhar sociológico pode trazer explicações subversivas sobre as relações sociais inerentes às formas de adoecer ou morrer no trabalho. (SOARES, 2014, p116)

Sabemos que o trabalho hoje tem um valor mercadológico e não há liberdade para a criação ou está inserido numa produção alienada, quando não se identifica com o que produz, porém, o homem necessita da venda da força de trabalho para a manutenção das necessidades físicas e sobrevivência na sociedade capitalista. Neste contexto a exploração e alienação da força de trabalho tira o seu sentido como propulsor do ser social. 
O homem na sua condição de trabalhador explorado frente ao capitalismo e as condições impostas, ainda assim, é um ser humano com a necessidade de socialização e, vemos então no trabalho a condição fundamental e natural da interação material entre o ser social, a natureza e a sociedade, porém, a mercantilização do trabalho traz um estranhamento demostrando um cenário de antagonismo. De acordo com Antunes (2005), “o trabalho tem uma dúplice e contraditória dimensão na medida em que possibilita criar, mas também subordinar, humanizar e degradar, libertar e escravizar, emancipar e alienar".

Neste sentido, na sociedade capitalista o indivíduo tem sua valia atribuída a capacidade de produzir, logo, os trabalhadores adoecidos, nesta lógica perdem a valoração, pois estão parcialmente excluídas do mercado de trabalho e de determinados grupos sociais, gerando a necessidade de segregação ocupacional, ou requalificação profissional para reingresso ao mercado de trabalho. Como vemos a seguir,

Portanto, o estar ou ter uma doença é uma contingência vital e social que, por juízo de valor da sociedade moderna do trabalho e de classe, tornou-se uma condição ou atributo permanente negativo que carrega consigo a acusação do sujeito ser socialmente um peso morto. Ou seja, são normais os que suportam agravos e agressões sem gemidos e protestos; são anormais, predispostos, suscetíveis, inadaptáveis, ou doentes os que não os aguentam e manifestam mal-estar e sofrimento (LOURENÇO et al., 2010, p.307, grifo do autor).

Indagando as perdas vivenciadas pelas trabalhadoras acometidas de doenças sócioocupacionais (doenças osteomusculares), abaixo apresentaremos os resultados da pesquisa, as narrativas e breves análises sobre trabalho, família e gênero.

\section{AS IMPLICAÇÕES SOCIAIS A PARTIR DO ADOECIMENTO E AFASTAMENTO LABORAL DAS TRABALHADORAS DO SETOR TÊXTIL DE BLUMENAU}

O município de Blumenau é considerado um dos principais pólos de produção têxtil e vestuarista no país, por localizar em seu território empresas como: Hering, Malwee, Teka, Sulfabril, Cremer, Karsten, Altenburg, Malharia Cristina, entre outras. Segundo Censo do IBGE, em 2010, Blumenau possuía 119.500 trabalhadores formais, destes 64\% atuam no setor têxtil-vestuário.

Na Empresa $^{3}$ estudada estima-se que em 2014 estavam empregados 550 trabalhadores, destes $10 \%$ apresentavam algum agravante de saúde, sendo 63\% doenças osteomusculares, $21 \%$ doenças psíquicas; $6 \%$ doenças neurológicas, $4 \%$ acidentes de trajeto, $6 \%$ outros agravantes de saúde. Cabe mencionar que $90 \%$ dos funcionários da empresa são do sexo feminino e que $100 \%$ das pessoas afastadas por doenças osteomusculares são mulheres. As doenças osteomusculares ocupacionais são

\footnotetext{
${ }^{3}$ Dados obtidos com a equipe técnica do ambulatório da empresa (2014). O nome da empresa pesquisada foi ocultado, por não haver autorização institucional de divulgação da informação.
} 
agravadas com o sistema de produção taylorista-fordista caracterizado pelo desempenho de tarefas repetitivas e intensificação do ritmo de produção.

A pesquisa foi dirigida a $20 \%$ das trabalhadoras afastadas por doenças osteomusculares, ou seja, 07 costureiras. $\mathrm{O}$ quadro abaixo expõe a caracterização de forma detalhada.

Tabela 1- Perfil dos entrevistados

\begin{tabular}{|c|c|c|c|c|l|l|l|}
\hline $\begin{array}{c}\text { Entre- } \\
\text { vistada }\end{array}$ & Idade & $\begin{array}{l}\text { Estado } \\
\text { civil }\end{array}$ & Filhos & $\begin{array}{c}\text { Idade dos } \\
\text { Filhos }\end{array}$ & $\begin{array}{l}\text { Situação da } \\
\text { moradia }\end{array}$ & Mora com & \multicolumn{1}{|c|}{ Escolaridade } \\
\hline 1 & 40 & Solteira & 3 & 14,16 e 18 & Alugada & Filhos & $\begin{array}{l}\text { Ensino Fundamental } \\
\text { incompleto }\end{array}$ \\
\hline 2 & 38 & Casada & 2 & 20 e 23 & Financiada & Marido e filhos & $\begin{array}{l}\text { Ensino Fundamental } \\
\text { Completo }\end{array}$ \\
\hline 3 & 36 & $\begin{array}{l}\text { União } \\
\text { Estável }\end{array}$ & 3 & 10,16 e 21 & Própria & Marido e filhos & $\begin{array}{l}\text { Ensino médio } \\
\text { Completo }\end{array}$ \\
\hline 5 & 29 & Casada & 1 & 6 & Própria & Marido e filho & $\begin{array}{l}\text { Cursando Ensino } \\
\text { Superior }\end{array}$ \\
\hline 6 & 27 & Casada & 1 & 9 & Própria & Marido e filho & $\begin{array}{l}\text { Ensino médio } \\
\text { Completo }\end{array}$ \\
\hline 7 & 25 & Casada & 1 & 8 & Própria & Marido e filho & $\begin{array}{l}\text { Ensino médio } \\
\text { incompleto }\end{array}$ \\
\hline
\end{tabular}

Fonte: A tabela foi organizada pelas autoras, a partir dos dados obtidos na pesquisa.

Sobre escolarização verificou-se que uma possui ensino fundamental incompleto, 01 ensino fundamental completo, uma ensino médio incompleto, três ensino médio completo e apenas uma trabalhadora está cursando o ensino superior.

Do vínculo empregatício com a empresa, quatro das entrevistadas tem de quatro á sete anos de tempo de atividade laboral naquela empresa e três das entrevistadas têm de oito a doze anos na empresa. Porém, do tempo que desempenha o ofício (costureira), constatou-se que três das entrevistadas desempenhavam de sete a dez anos antes de entrar na empresa atual.

Referente ao período de afastamento das atividades laborais para tratamento de saúde, quatro das pesquisadas tem de sete meses a três anos e as outras três possuem cinco a seis anos de afastamento de trabalho, sendo que todas atuavam como costureiras na empresa.

Dos dados referentes às causas do afastamento, apenas uma das entrevistadas constatou doença osteomuscular nos membros inferiores (joelho), as demais relataram nos 
membros superiores, braço, punho, ombro e cotovelo. Das entrevistadas apenas duas já haviam sido afastadas das atividades laborais em outra ocasião, porém, não pelos mesmos motivos.

Em relação ao tratamento de saúde, vemos que das entrevistadas temos uma das trabalhadoras que opta por tratamento particular e outra somente pelo Sistema único de Saúde (SUS), as demais mesclam atendimentos pelo SUS, convênio sindical e ou convênio com plano de saúde empresarial. Porém, os medicamentos utilizados para o tratamento de saúde são comprados por parte de todas as entrevistadas. De acordo com relatos por parte de algumas das trabalhadoras, os medicamentos fornecidos pelo SUS não tinham o mesmo efeito que os adquiridos de maneira particular.

Observou-se ainda, que fatores como a demora e demasiada burocratização nos atendimentos, agendamentos com especialistas, obtenção de medicamentos ou outros exames e/ou tratamentos complementares, foram identificados no relato de todas as entrevistadas. Umas das entrevistas relatou que seu médico de referência lhe advertiu da ineficácia dos medicamentos ofertados na rede pública, e se mesmo assim optasse por eles deveria tomar em dose muito maior em comparação ao adquirido de maneira particular.

Logo, podemos perceber que a ineficiência e precarização da saúde pública implica no não-reestabelecimento da saúde destas trabalhadoras lesionadas por doenças ocupacionais, e assim, ainda contribui com aumento no gasto previdenciário, tendo em vista que o estado de adoecimento e a momentâneo e ou permanente incapacidade laborativa se mantém ou agravase devido ao não tratamento de saúde adequado e imediato.

No que tange os sintomas das doenças osteomusculares, todas as descrições se aproximam, os sintomas variam entre dor, formigamento, queimação, imobilidade, falta de firmeza nas mãos, inchaço e desconforto. Os sintomas podem ter alteração de intensidade e na manifestações das tipologias dos sintomas, assim como o grau de inflamação dos membros lesionados.

Sinto muita dor, não posso nem pentear meus cabelos ou trocar de roupa, graças a Deus tenho muitas amigas que vem me ajudar. (E2)

Do mesmo modo reforça (E5),

O nervo começou a romper e cada vez inflama mais e cada vez que rompe mais, eu vou perdendo o movimento da mão e cinto muita dor a noite e se fazer um esforço em um dia no outro da muita dor. 
Vemos ainda conforme (E7),

A dor não passa e eu não tenho o que fazer e no começo que descobri a doença da mesma forma ainda fazendo tratamento eu estava trabalhando na empresa, até a hora que eu não conseguia mais levantar o braço dai me afastaram.

Percebe-se então, que diante destes sintomas, na ausência do bem-estar físico e mental acarreta prejuízos ao bem estar do indivíduo, a presença da dor passa a ser rotineira, ocorre então um processo de naturalização dos sintomas e a privação de qualidade de vida da trabalhadora lesionada e traz reflexos ao convívio familiar. As limitações físicas vão alterando seu modo de viver. As tentativas de conter, controlar e minimizar a dor com ingestão de analgésicos que atenuam os sintomas e até mesmo comportamentos de tolerância à dor fica evidenciado, por parte das trabalhadoras. Houve relatos referindo que as dores eram presentes há anos, mas o tratamento adequado só ocorreu quando não houve mais condições de desempenhar suas atividades. Vemos ainda,

Para as mulheres, e aqui se está falando das classes populares, não se trata de evitar a doença, o problema é domesticá-la, contê-la, controlá-la, viver com ela. As mulheres, dizem, são todas doentes, mas essas doenças são de alguma maneira, mantida à distância pelo desprezo. Somente são reconhecidas aquelas que se exprimem por sintomas muito evidentes, que signifique uma síndrome deficitária grave. Para que uma doença seja reconhecida, para que se resigne a consultar um médico, para que se aceite ir ao hospital, é preciso que a doença tenha atingido uma gravidade tal que ela impeça a continuidade seja da atividade profissional, no caso dos homens, seja nas atividades domésticas e familiares, no caso das mulheres (Dejours, 1987,p.30).

Desta forma, percebe-se o processo naturalização dos prejuízos a saúde do trabalhador em decorrência de seu trabalho.

Eu estou assim por causa da profissão, todos veem isso e tem consciência, mas lá dentro eles não querem nem saber, minha encarregada sempre dizia se não é para produzir então vai embora. (E5)

O trabalhador se submete as condições de trabalho oferecidas e as exigências do empregador, com atividades de alta produtividade, movimentos repetitivos, serviços monótonos e exaustivos que oferecem risco a saúde dele.

O sofrimento é, pois uma realidade concreta e não desejada, expressa em sensações, mudanças corporais, mentais e comportamentais que impõe limitações físicas, psíquicas e afetivas que mudam a vida da pessoa. A contragosto, desonera-a da dinâmica social a que estava habituada, traz-lhe culpa e sensação de desamparo, impondo-lhe um modo de vida sofrido que transcende o simples desvio de padrões fisiológicos que sequer conhece. (LOURENÇO et al., 2010, p.308) 
$\mathrm{Na}$ busca por atenuar a dor e lutar contra a evolução das doenças osteomusculares, todas relataram fazer tratamento medicamentoso. Sendo que, das entrevistadas a ingestão dos medicamentos vária de dois a oito tipologias de medicamentos ao dia.

Foi identificado também que a maior parte das pesquisadas faz tratamentos auxiliares por indicação médica, uma delas faz tratamento com endocrinologista, outras duas referiram fazer fisioterapia e outra infiltração articular a cada seis meses.

Das pesquisadas, uma delas já foi submetida a procedimento cirúrgico (por meio do plano de saúde), e as outras cinco relataram estar aguardando cirurgia, apenas uma referiu não haver esta indicação médica. Das que aguardam cirurgia, estão em espera para que o procedimento ocorra através da rede pública, SUS. Identificou-se algumas das trabalhadoras aguardando agendamento para cirurgia dos membros lesionados, uma delas relatou estar aguardando na fila acerca de 5 anos.

As recomendações médicas para contribuir com tratamento de saúde, são muito semelhantes, referem-se a evitar movimentos, não erguer peso e manter repouso.

Pego o ônibus todo o dia para fazer fisioterapia, mas o médico disse que eu preciso evitar qualquer tipo de movimento no braço, até andar de ônibus ele disse pra evitar, porque o sacolejo do ônibus pode romper o tendão aí eu vou ficar com o braço morto sem movimento nenhum. (E2)

Todas trabalhadoras relataram não conseguir cumprir as recomendações medicas de forma integral, pois até a higiene pessoal já descumpre as recomendações médicas. As atividades da organização do lar e cuidado com filhos também é frequente, e percebido pelas entrevistadas como um dificultador na medida em que implicam na recuperação das mesmas.

Não consigo seguir, pois preciso mexer o braço até para fazer minhas higienes pessoais. (E3)

Vemos aqui, a questão de gênero como agravante da situação de saúde, pois se mostra prejudicial a execução do tratamento de saúde conforme fora recomendado. Desta forma, impede que a mulher se constitua e se perceba enquanto sujeito de direitos, devido a forte influência da cultura machista e patriarcal, que atribui exclusivamente a mulher a administração e execução das atividades domésticas. A impossibilidade de exequibilidade destas funções corrobora com o sentimento de frustração diante do seu papel frente a sociedade e família. 
Outro fator relevante identificado, foi que o benefício auxílio-doença acessado pelas trabalhadoras adoecidas, tinha valor mensal inferior em relação ao salário que recebiam habitualmente. $\mathrm{O}$ valor da depreciação salarial de acordo com as entrevistadas é em média de $\mathrm{R} \$ 300,00$ a $\mathrm{R} \$ 400,00$.

Além disso, os custos médios mensais foram maiores, devido á necessidade de aquisição de medicamentos e outros gastos com o tratamento, alguns casos, gasto com "diarista" semanalmente para os afazeres domésticos, em outros casos, despesas com transporte para o deslocamento ás consultas médicas e seções de fisioterapia.

Em relação à responsabilidade dos afazeres domésticos, seis relataram que ainda o fazem, porém, as atividades mais complexas que necessitam de mais força e agilidade transferem á familiares. Do preparo das refeições, todas relataram fazê-lo e cuidado com os filhos menores também.

Conseguir limpar a casa eu até consigo, minha casa não é grande, mas depois eu sinto muita dor, já fui parar no pronto socorro por isso. (E5)

Percebeu-se uma responsabilização pelos afazeres domésticos à mulher, no cuidado do lar, dos filhos e responsável no preparo dos alimentos da família. De maneira que ao necessitar da contribuição de familiares (marido, filhos, pais), no âmbito doméstico com os afazeres, repetidamente se ouvia estas os agradecendo pelo favorecimento e demostravam sentimento de culpa ou dívida com seus cônjuges. Neste aspecto, identificou-se comportamentos que conotam sentimentos de angustia, frustração, insegurança e culpa pelas entrevistadas.

Não posso mais fazer as coisas do meu jeito, tenho que ficar contente com o que os outros fazem, eu tinha mania de limpeza agora sou obrigada a conviver com isso. (E2)

E ainda de acordo com (E7),

Eu tenho que fazer a comida pra minha filha quando chega do colégio e eu não posso deixar todo o serviço da casa pro meu marido que trabalha fora o dia todo.

Para tanto, podemos compreender que o afastamento para tratamento de saúde do ambiente de trabalho para a mulher é mais complexo. Pois, este não se dá plenamente, haja vista os papéis pré-estabelecidos na sociedade e as obrigações no ambiente doméstico que são atribuídas às mulheres a partir de uma construção social/cultural de valores e condutas. 
Observou-se que houve mudanças na rotina de todas as entrevistadas, com ênfase à diminuição ou perca da destreza nas atividades no âmbito doméstico.

É muito ruim né, a gente se sente incompetente, assim, perdi as contas do tanto de vezes que deixei forma quente ou panela quente cair nas minhas pernas, perco as forças nas mãos, minhas pernas são todas marcadas, sinto saudades de andar de bicicleta que também não dá mais. (E2)

E ainda, os impactos desta situação na saúde emocional, são muito visíveis, que fazem menção a imagem que este indivíduo tem de si, além dos sentimentos negativos já mencionados. Desta forma, ficam evidente as consequências nocivas acarretadas a vida das trabalhadoras neste contexto e circunstância. Tais mudanças podem influir numa crise de identidade e atingir as expectativas e regras sociais sobre homens e mulheres reconhecidas pelos indivíduos. Merlo et al. (2001) afirmam que o desencadeamento das doenças do trabalho podem refletir em distintos aspectos:

Os indivíduos expressam sentimentos de desvalia, insegurança quanto ao futuro profissional, inconformismo diante de algumas limitações, incertezas e morosidade no processo terapêutico e de reabilitação, medos e fantasias inconscientes, manifestações depressivas e de revolta associadas, em geral a incorporação de toda uma ideologia de culpabilização individual. (p. 243)

Em relação à reação dos familiares nesta situação de limitações ocasionadas pelas doenças osteomusculares, todas relataram que eles entendem bem e colaboram na medida do possível. Em nenhuma das situações se pode averiguar cônjuges ou familiares que assumisse todos os compromissos dos afazeres domésticos, houve responsabilizações parciais e não integrais como o faz a mulher em seu papel convencional na sociedade.

O afastamento dos colegas de trabalho também foi relatado como uma das consequências nocivas do fenômeno a qual vivenciam, apenas duas das entrevistadas relataram ainda manter relação com as colegas de trabalho. Compreendemos que "Socialmente, a doença é um estado provisório ou definitivo de exclusão" (Lourenço et al., 2010). Então, esta situação de afastamento do trabalho reflete numa forma de isolamento ou negação do convívio social,

Além de gostar de trabalhar a relação com elas era muito boa agora somente posso ir até na casa da minha cunhada que é minha vizinha. (E1)

Deste modo, vemos ainda:

[...] todo ato de trabalho resulta em consequência que não se limitam à sua finalidade imediata. Ele possibilita o desenvolvimento das capacidades humanas, 
das forças produtivas, das relações sociais, de modo que a sociedade se torne cada vez mais desenvolvida e complexa (LESSA, 1999, p. 25-26).

Segundo Amaral, um estudo realizado a fim de compreender possíveis impactos psicossociais advindos desta situação, trouxe dados muito interessantes:

Entre outros elementos, os resultados indicaram um alto grau de sofrimento nos três casos analisados e demostram crise de subjetividade em todas as dimensões psicossociais avaliadas: vida pessoal, sociabilidade, autorreferência, projetiva e crítica. (AMARAL, 2014, p 120)

Igualmente podemos perceber na fala de uma das entrevistadas (E4)

A gente se sente um nada, tem uma vida sedentária, engordei muito, minha autoestima está lá em baixo, dependo dos outros para ver minha casa limpa.

Percebeu-se também que as trabalhadoras "improdutivas" são alvo de preconceito, por colegas de trabalho, pelo empregador e demais membros da sociedade. Houve relatos relacionados ao modo de atendimento "abrupto" dos médicos peritos do Instituto Nacional de do Seguro Social (INSS). Deste modo, o sentimento de culpa ou vivencia de situações de preconceito, são reforçados pela alocução dos médicos peritos do INSS, com relatos marcados por sentimentos de humilhação, desrespeito e desprezo, diante das mostras de descrédito por parte dos profissionais lá atuam, que marca a relação com a perícia.

Fui buscar o resultado do meu exame e o rapaz me falou é para você e eu disse sim, então ele respondeu é mais nem parece, daí eu mostrei meu braço para ele todo inchado e roxo daí ele me pediu desculpas. E na própria empresa os colegas de trabalho me diziam: malandro tem sorte mesmo. (E7),

E relata ainda $(\mathrm{E} 6)$,

Quando vou ao INSS eles me taxam como preguiçosa, pois dizem que isso não é nada e mesmo na empresa eles querem que nós pedimos a conta.

De encontro com esta realidade, afirma o autor que "[...] a Previdência Social e o campo da saúde do trabalhador tem se direcionado pela lógica economista de contenção de custos, afastando-se do atendimento às reais necessidades de seus usuários". (PEREIRA, 2014, p.131)

Tal conjuntura favorece um processo de descrença, desconfiança e preconceito pelos demais em relação aos sintomas ou limitações das doenças osteomusculares, desconsiderando deste modo à existência das peculiaridades que compõe este contexto de agravo da saúde do trabalhador. Vemos que em concordância com (Lourenço et al., 2010) “(...) o que faz adoecer alguns pode não adoecer outros e os que adoecem o fazem de modo diferentes; isto é, cada sujeito tem um modo particular de reagir, de adoecer ou não adoecer". 
Deste modo, como resultante destas circunstâncias, imprimi na vida destes trabalhadores "inativos" a sensação de culpa, apreensão e marginalização por sua situação de falta de saúde, que acarreta na parcial ou total exclusão de determinados grupos sociais e ainda torna-os passiveis de situações constrangedoras e vexatórias.

Eu ia ao sindicato e um dia uma mulher que trabalha na empresa disse que era doença de malandro por que ela trabalhava lá a muito tempo e nunca deu isso nela. (E2)

E conforme relato da (E4),

Para os ex-colegas de trabalho e dos próprios colegas que não conhecem as doenças,

Vemos ainda, se você sorrir é por que não está doente.

(...) as doenças não se manifestam de modo igual; primeiro porque os sujeitos, mesmo quando são irmãos univitelinos, não são clones, apesar de ter constituintes orgânicos e inorgânicos parecidos ou comuns; segundo por que os agravos a que se vêm obrigados a expor no trabalho e fora do trabalho diferem qualitativamente, quantitativamente no tempo e no lugar; terceiro porque as alterações anatômicas, fisiológicas, psíquicas e afetivas ocorridas com os adoecidos raramente guardam relação simétrica com tais agravos, ou seja, por trás há uma causalidade mais profunda, insuficientemente conhecida, oculta e ocultada. (LOURENÇO et al., 2010, p.309)

As mulheres entrevistadas foram indagadas a respeito da intensão de retorno a mesma atividade laboral e profissão se reabilitadas, três destas responderam que sim e as demais afirmaram que não. Algumas relataram que tiveram um posicionamento negativo por parte dos médicos que acompanham sua situação de saúde, em relação ao retorno da atividade da profissão habitual. As demais relataram que voltariam para mesma profissão, em decorrência da falta de qualificação para outra área. Então, podemos apontar a falta de expectativas pessoais/profissionais como fator preponderante nas (não) projeções de um futuro diferente ou pode-se dizer com maior qualidade de vida. Algumas delas dizem haver impedimentos de ordem física, outras referiam-se a outros fatores; socioeconômicos, distante localização de moradia, limitação dos meios de locomoção, compromisso com o cuidado dos filhos entre outros que somam como agravantes nesta conjuntura de falta de vislumbre de mudanças.

Depois que eu fizer a cirurgia no meu olho e voltar a enxergar melhor, vou ver se tenho condições, antes nem pensar. (E1)

Relata ainda (E2),

Agora não, pois o meu acesso à cidade é muito ruim para isso. Quase não tem horários de ônibus.

Conforme a explanação do autor vemos então que; 
O estado conjugal e a presença de filhos, associados à idade e à escolaridade da trabalhadora, as características do grupo familiar, como o ciclo de vida familiar em formação, com filhos pequenos, famílias maduras, filhos adolescentes, famílias mais velhas, e a estrutura familiar - família conjugal, chefiada por mulher, ampliada, presença de outros parentes - são fatores que estão sempre presentes na decisão das mulheres de ingressar ou permanecer no mercado de trabalho, embora a necessidade econômica e a existência de emprego tenham papel fundamental (Bruschini, 1998:4).

Foi perceptível na fala das entrevistadas, um fator cerceador desta qualificação ou requalificação profissional, a limitação física advinda das doenças osteomusculares. Com o grande número de lesionamento dos membros superiores, isto impossibilita a mobilidade das mãos e braços para a escrita ou digitação, que são utilizados como meios tradicionais de ensino. Demostrando nisto, uma problemática implicada para as mulheres nesta situação, mostrando-se uma questão desafiadora para a qualificação/requalificação profissional ou a reinserção no mercado de trabalho.

Até pensei em fazer algum curso né, mais, tem que escrever e eu não consigo mais, às vezes nem assinar meu nome dá. (E7)

Vale acrescentar ainda, assim como as relações de exclusão social e segregação ocupacional que lhe são subjacentes, isto remete-lhes à novas condições de organização do trabalho ou reinserção no mercado de trabalho. Então devemos aqui, pontuar a pouca diversidade de oferta de trabalho/atividades laborais (nos setores de trabalho) ás mulheres com menor qualificação profissional, em particularidade na nossa região onde o setor têxtil predomina. Percebe-se aqui outro fator dificultador na perspectiva da reinserção profissional para reabilitados ao trabalho com restrições de movimento e ou em funções compatíveis com a atual situação clínica do trabalhador.

O médico do sindicato me colocou em uma reabilitação para voltar a trabalhar, mas o médico da empresa disse que não tem o que fazer na empresa, pois corro o perigo de romper o outro tendão daí eu fico nessa sem saber o que vai acontecer. (E6)

Então, sabedores das limitações físicas á elas implícitas que percebemos em sua maioria acometer os membros superiores surgem à preocupação da reinserção no mercado de trabalho, adequado à sua nova realidade, tendo em vista que estas trazem consigo as marcas da precariedade do trabalho. Então vemos que,

(...) o campo de atuação da mulher fora do lar circunscreveu-se ao de ajudante, assistente, ou seja, a uma função de subordinação a um chefe masculino em atividades que as colocaram desde sempre à margem de qualquer processo decisório. No caso da operária, mesmo num ramo onde sua participação era enorme, como o têxtil, as alternativas de ocupação para os homens eram maiores. Enquanto eles estavam presentes em quase todas as atividades ocupadas pelas mulheres, como a 
costura de sacos ou nas maçaroqueiras, vários trabalhos eram interditados a elas, principalmente os cargos de chefia. (RAGO, 1997, p. 65)

Quando questionadas em qual campo gostariam de fazer a requalificação profissional, todas relataram não saber, demostravam sentimento de dúvida referiam nunca ter pensado nesta hipótese, demostrando que isto não havia sido ideado por estas mulheres.

Até pensei em fazer um curso, mas dai se eu fizer um curso que eu não gostar e eles cortarem meu benefício por causa disso? Já ouvi falar disso. Vou ter que pedir a conta. (E6)

Deste modo, fica evidenciado que o sofrimento advindo deste processo de trabalho acelerado ou fatores correlacionados ao trabalho é imperceptível ou visto com naturalidade aos olhos da sociedade, pois tende a ser visto como um problema individual. Vemos a questão do individualismo e culpabilização da vítima como agravante neste contexto acarretando a exclusão social. Sendo este um campo legalmente tenso para a relação com o empregador, o qual pode induzir na formação de uma opinião pública hostil aos trabalhadores adoecidos e, por extensão, a todos os trabalhadores (LOURENÇO, 2010), considerando que implica questões judiciais e previdenciárias.

\section{CONSIDERAÇÕES FINAIS}

Essa pesquisa abriu a possibilidade de discutir os múltiplos fatores no entorno da problemática do adoecimento do trabalhador, desde suas limitações físicas, os sintomas e reflexos no contexto social/pessoal e profissional, relacionadas a questão de gênero.

Pudemos observar também que a questão de gênero perpassa como agravante no adoecimento laboral e no processo de reabilitação destas trabalhadoras.

As limitações impostas pela condição de empobrecimento e exploração que se encontra a mulher na sociedade contemporânea, a qual necessita vender sua força de trabalho no espaço fabril, para conquistar maior autonomia e ainda desenvolver inúmeras atividades á ela atribuídas no âmbito familiar acarretam prejuízos na sua condição de adoecimento e ou reabilitação.

Sabedores da concepção de importância deste papel no âmbito do lar à estas mulheres essa tornou-se uma característica de identidade da mulher na sociedade, e a partir da 
problemática apresentada compreende-se então um insegurança quanto a sua função social, gerando ambiguidade de sentimentos e refletindo numas crise de autoreferência.

Diante do exposto, concluímos que as mulheres acometidas por doenças ocupacionais e afastadas das atividades laborais em decorrência deste fenômeno vivenciam inúmeros prejuízos, entre eles: físicos, pessoais, profissionais, sociais, econômicos e emocionais.

\section{REFERÊNCIAS}

ANTUNES, R. Adeus ao trabalho? Ensaio sobre as metamorfoses e a realidade do mundo do trabalho. $9^{a}$ ed. São Paulo: Cortez: Campinas (SP): Editora Estadual de Campinas, 2009.

O caracol e a sua concha: ensaios sobre a nova morfologia do trabalho. São Paulo: Boitempo, 2005.

AMARAL.A.L.V. Trabalho e saúde do trabalhador. In: Seminário do trabalho: trabalho, educação e neodesenvolvimentismo, IX. 2014“(In)capacitados para o trabalho”? Trabalho, estranhamento, e saúde do trabalhador no brasil (2000-2010). Marília SP: Promoção RET/GPEG- UNESP.

BRASIL.IBGE. Censo Demográfico, 2010. Disponível em: 〈www.ibge.gov.com.br.> acessado em: 04 jun. 2015.

BRUSCHINI,C- Gênero e Trabalho Feminino no Brasil: novas conquistas ou persistência da discriminação? Brasil, 1985-1995- Paper apresentado no seminário Trabalho e Gênero: Mudanças, permanências e desafios. GT População e Gênero Nepo/Unicamp, São

Paulo,1998.

DEJOURS, C . A Loucura do Trabalho . Oboré, São Paulo, 1987.

LESSA, S. O processo de produção/reprodução social: trabalho e sociabilidade. Brasília: CEAD, 1999, p. 20-33.

LOURENÇO, E. O avesso do trabalho II: Trabalho, precarização e saúde do trabalhador. $1^{\text {a }}$ ed. São Paulo: Expressão popular. 2010.

SOARES,E.L.A. Trabalho e saúde do trabalhador. In: Seminário do trabalho: trabalho, educação e neodesenvolvimentismo, IX, 2014. O adoecimento laboral como problema social: Notas para uma explicação sociológica. Marília/SP: Promoção RET/GPEG- UNESP.

PEREIRA, M.C.C. Trabalho e saúde do trabalhador. In: Seminário do trabalho: trabalho, educação e neodesenvolvimentismo, IX, 2014. Processo saúde-doença sob a ótica do campo saúde do trabalhador e Previdência. Marília SP: Promoção RET/GPEG- UNESP. 
MERLO, A. R. C., Jacques, M. G. C., \& Hoefel, M. G. L. Trabalho de grupo com portadores de LER/DORT: relato de experiência. Psicologia: Reflexão e Crítica, 2001.

RAGO,M. Trabalho feminino e sexualidade. In:DEL PRIORE, M. (Org.).História das Mulheres no Brasil. São Paulo: contexto, 1997. 